\title{
Ellen Widder, Kanzler und Kanzleien im Spätmittelalter
}

Pierre Monnet

\section{OpenEdition \\ Journals}

Édition électronique

URL : http://journals.openedition.org/ifha/9467

DOI : $10.4000 /$ ifha. 9467

ISSN : 2198-8943

Éditeur

IFRA - Institut franco-allemand (sciences historiques et sociales)

\section{Référence électronique}

Pierre Monnet, «Ellen Widder, Kanzler und Kanzleien im Spätmittelalter », Revue de l'IFHA [En ligne], Date de recension, mis en ligne le 23 août 2018, consulté le 24 septembre 2020. URL : http:// journals.openedition.org/ifha/9467 ; DOI : https://doi.org/10.4000/ifha.9467

Ce document a été généré automatiquement le 24 septembre 2020.

(CIFHA 


\title{
Ellen Widder, Kanzler und Kanzleien im Spätmittelalter
}

\author{
Pierre Monnet
}

\section{RÉFÉRENCE}

Ellen Widder, Kanzler und Kanzleien im Spätmittelalter. Eine histoire croisée fürstlicher Administration im Südwesten des Reiches, Stuttgart: Kohlhammer (Veröffentlichungen der Kommission für geschichtliche Landeskunde in Baden-Württemberg, Reihe B, Forschungen 204), 2016, 602 p., $49 €$ 
Le titre de cette volumineuse étude issue des travaux d'habilitation de son auteure pourrait laisser croire à une analyse très classique et traditionnelle: le milieu des chancelleries princières de la fin du Moyen Âge, en l'occurrence à l'image des territoires du Sud-Ouest de l'Empire aux $\mathrm{XIV}^{\mathrm{e}}$ et $\mathrm{XV}^{\mathrm{e}}$ siècles et de sa principauté dominante, le comté palatin. Sur le plan formel, tout porte également à le penser : une écriture dense, un déluge de noms et de faits (60 pages de registre), une bibliographie exhaustive et pointilleuse (80 pages de sources et de littérature secondaire), une dizaine d'images en noir et blanc, deux bons milliers de notes de bas de page... bref, le témoin supplémentaire d'une érudition et d'une rigueur toutes germaniques qui épuisent à peu près tout un sujet pour les décennies

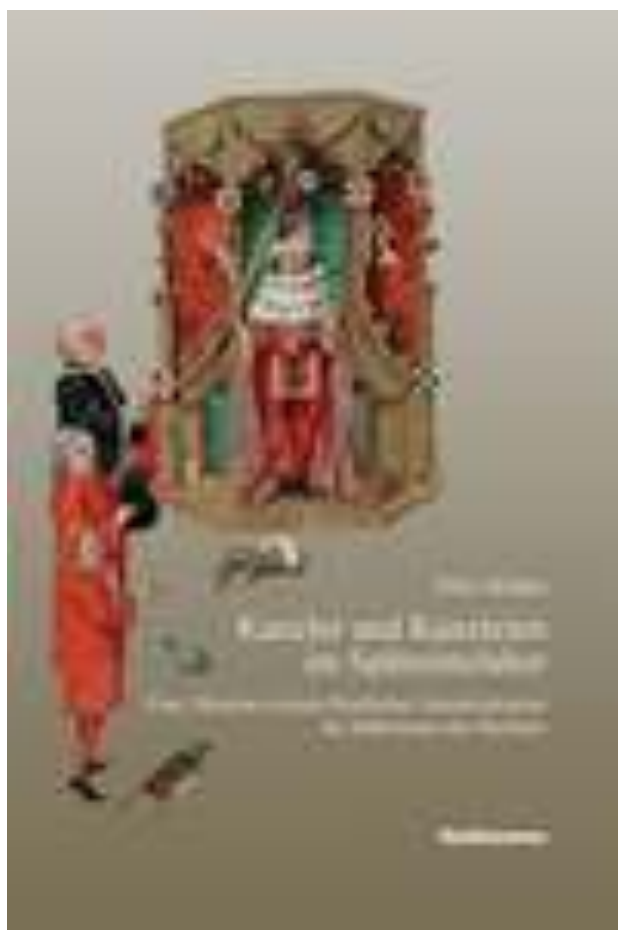
suivantes.

Pourtant, dès l'entame de la lecture on comprend que l'objet traité, la chancellerie, est placé au cœur d'une interrogation qui croise les points de vue entre histoire sociale des acteurs (avec force prosopographie pour éclairer un milieu), histoire de l'écrit, histoire du droit et des institutions, histoire culturelle du savoir... Plutôt que de décrire une institution figée, l'auteure érige sa matière en un lieu anthropologique et historique qui reflète les grandes évolutions du temps : maturation de l'écrit de l'enregistrement, du notariat et du diplôme ; bricolage et innovation institutionnels et politiques, premiers pas d'une administration étatique; mise en place du pouvoir territorial et princier; chances et limites d'une carrière au service du prince (ici les comtes palatins, des princes-électeurs depuis 1356...) ; affaires d'argent aussi, de rapports de pouvoir forcés ou négociés. De tout cela la chancellerie devient à la fois le support, le vecteur et l'observatoire, suivant une pente historiographique dont Ellen Widder avoue s'être inspirée à la source des travaux français. La question posée, on l'aura compris, n'est plus tant celle de savoir ce qu'était la chancellerie d'un prince comme le comte Robert devenu roi de 1400 à 1410 ou Frédéric le Victorieux (1451-1476), mais quelle culture politique, administrative, savante et juridique reflète une telle institution avec ses réseaux, ses relais, ses antennes spatiales, financières et symboliques.

Une telle approche ne signifie pas que l'auteure renonce aux outils classiques et parfois très érudits de l'histoire des actes (codicologie, diplomatique, archivistique, paléographie etc.), mais que cette connaissance fine et technique des milliers d'actes produits par une chancellerie sur 150 à 170 années se place au service d'une dynamique portée par la volonté du prince, par l'action de son chancelier de ses scribes (qui forment une sorte de cour dans la cour), par la logique contrôlée ou incontrôlée de l'écriture des actes, de leur diffusion, de leur conservation et de leur remploi, par les effets de juridisation, de procédurisation, d'universitarisation et de monétarisation de la société qu'ils reflètent et amplifient tout ensemble. 
De la sorte, cette étude ne relève pas seulement de l'histoire régionale si chère encore à la tradition historique allemande, mais propose un ensemble d'outils et d'interprétations ouverts à la comparaison, à laquelle l'auteure sacrifie volontiers en regardant parallèlement du côté des autres chancelleries de l'Empire mais aussi du royaume de France ou d'Italie au même moment, érigeant la chancellerie princière au rang de fabrique et de relais indispensables de la modernisation des États prémodernes européens, et tout cela dans une histoire qui ne fait pas de l'Empire un Sondermodell mais une variante parfaitement intégrée. Ce faisant, l'auteure aborde et discute des concepts tels que la formation des élites, le phénomène de génération, les effets de domination par l'écrit, les rapports entre clercs et laïcs au sein d'une même culture savante, mais aussi de dignité du service public; toutes notions appartenant à une histoire $d u$ politique qui, à en juger par ce livre, conserve encore un bel et fructueux avenir historiographique.

\section{INDEX}

Index chronologique : Moyen Âge

Thèmes : Histoire des États et des pouvoirs, Histoire sociale, Histoire du droit

\section{AUTEURS}

PIERRE MONNET

EHESS (Paris) et IFRA-SHS (Frankfurt am Main) 